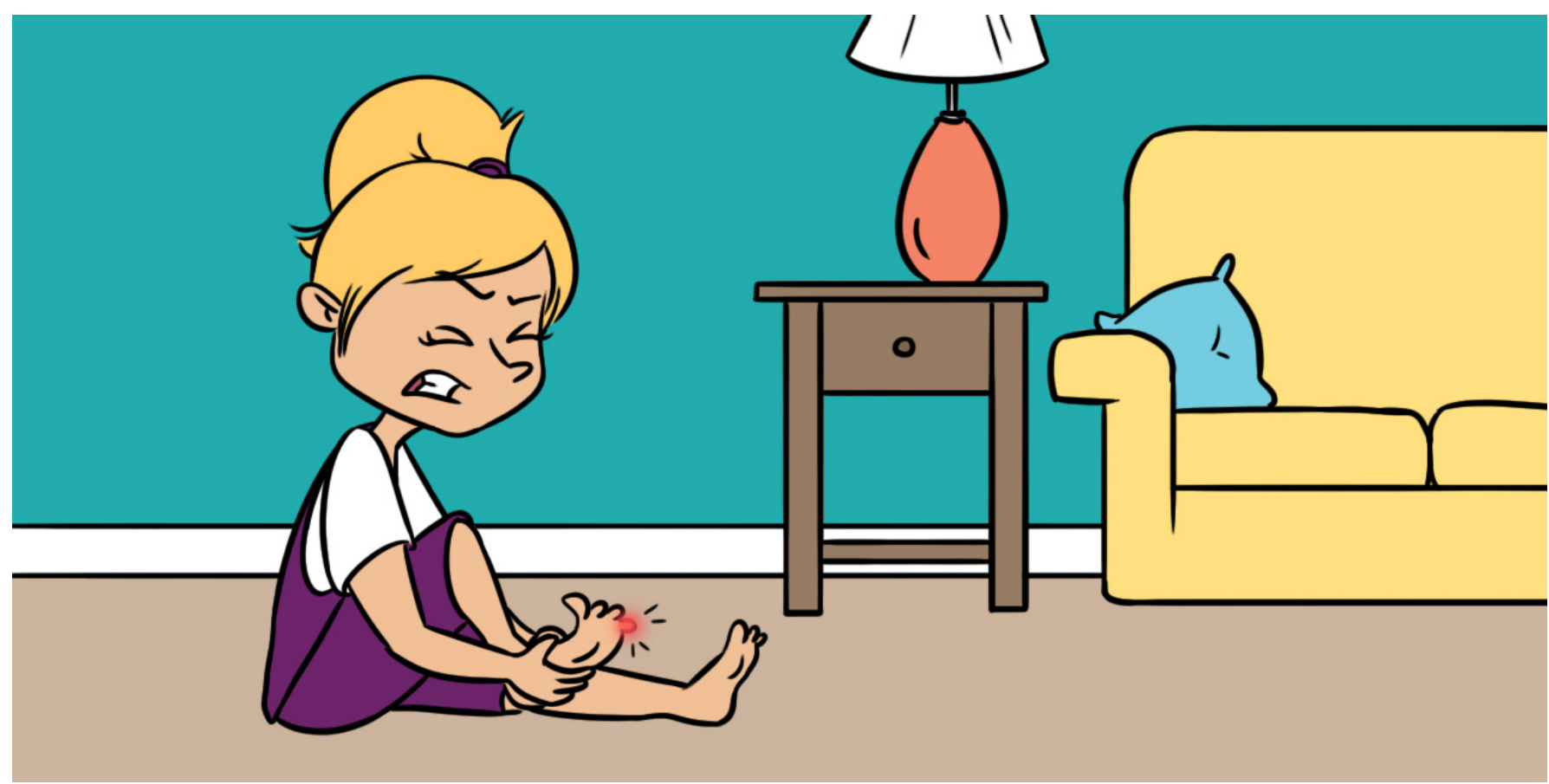

\title{
MAY INFLAMMATION BE WITH YOU!
}

\section{Trinidad Montero-Melendez ${ }^{1,2 *}$}

${ }^{1}$ The William Harvey Research Institute, Barts and The London School of Medicine, Queen Mary University of London, London, United Kingdom

${ }^{2}$ Centre for Inflammation and Therapeutic Innovation, Queen Mary University of London, London, United Kingdom

\section{YOUNG REVIEWERS:}

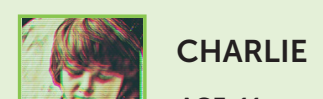

AGE: 11

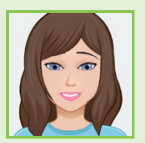

ELIANA

AGE: 11

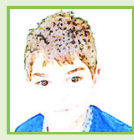

MILAN

AGE: 9

RAFAEL

AGE: 10
Inflammation is a protective reaction of the body against injury or infection, in which the affected area becomes swollen, hot, red, and painful. In the past, it was believed that this reaction was dangerous and that anti-inflammatory medicines were necessary. However, we now recognize inflammation as a protective and necessary response of our internal defense system, and we know that it may not always be good to block it. Recently, scientists have discovered a new component of the inflammatory reaction, called the "pro-resolving" program, which stimulates wound healing and repair of the damaged tissue or organ. By studying this pro-resolving program, scientists are developing a brand new class of medicines to use when we suffer from inflammation, which will make our bodies heal faster. Although they are still experimental, many scientists around the world believe that these will become the medicines of the future. 


\section{INFLAMMATION}

A protective reaction of the body against injury or infection, in which the affected area becomes swollen, hot red, and painful.

\section{Figure 1}

The pillars of inflammation The four major characteristics of inflammation were described by Aulus Cornelius Celsus more than 2,000 years ago and include redness (caused by dilation of small blood vessels), swelling (caused by the accumulation of fluid outside the blood vessels), pain (caused by chemical substances such as prostaglandins), and heat (resulting from increased blood flow).

\section{WHAT IS INFLAMMATION?}

\section{The Pillars of Inflammation}

The word inflammation comes from the Latin word inflammare (meaning "to set on fire"). The Roman writer Aulus Cornelius Celsus, who lived in the $1^{\text {st }}$ century $A D$, was the first to describe the process called inflammation. Inflammation is the reaction of the body against injury or infection [1]. For example, during a toothache, or sore throat, or when you hit your head on a door or badly stub your pinky toe, what your body experiences is called an inflammatory reaction. The affected area turns red, it gets hot, it swells up, and it hurts. These are the four major characteristics of inflammation described by Celsus almost 2,000 years ago, which is known as The Pillars of Inflammation: rubor (redness), calor (warmth) tumor (swelling), and dolor (pain) (Figure 1). Redness occurs because the capillaries (small blood vessels) in the affected tissue enlarge and bring in more blood than usual. This increase in blood flow is also responsible for the sensation of heat. Swelling happens because the tissues fill with liquid that comes out of the enlarged blood vessels. The pain sensation is caused by chemicals that stimulate the nerves endings in that area.

\section{Inflammation, Good or Evil?}

But, what is the purpose of inflammation? Why do we need to feel pain? Pain is essential to alert our bodies that something wrong is going on,

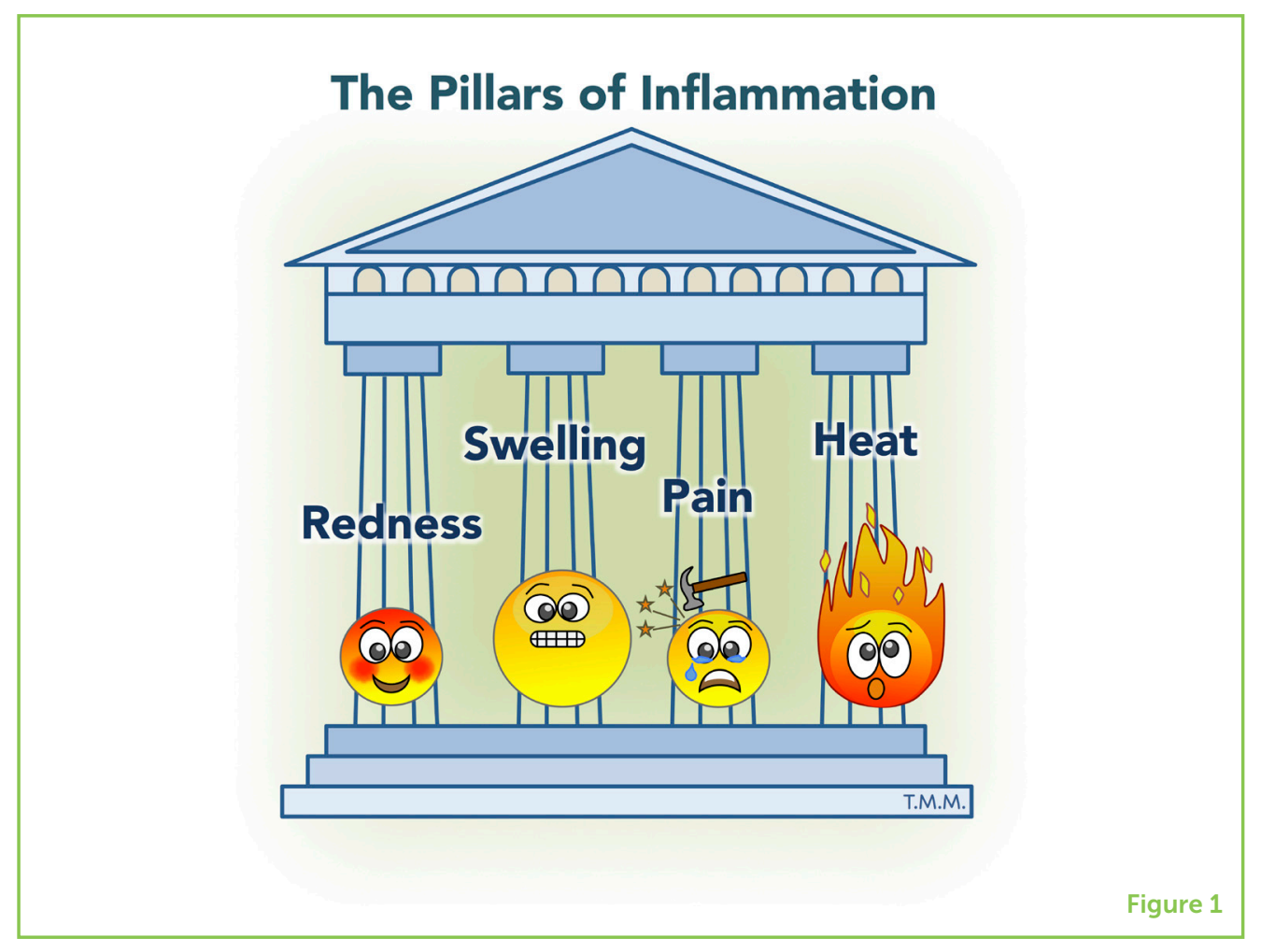




\section{IMMUNE CELLS}

The body's sentinels circulating in the bloodstream, responsible for the protection and defense of the body. There are many types of immune cells, including granulocytes (neutrophils, eosinophils, and basophils) and mononuclear cells (monocytes and lymphocytes).

and pain lets us know that a particular part of the body needs extra care. The other three factors (heat, redness, and swelling) are equally important, because they allow the immune system to come into action. The expansion of the capillaries and the increased blood flow bring the immune cells, such as neutrophils and monocytes, into the affected area. These immune cells are our internal warriors. They are the fighters that protect us against the agents causing the inflammation, such as the flu virus causing the sore throat or bacteria that are trying to enter the body through a wound in the skin. This protective function of inflammation, although it is very clear to us now, was not discovered until the nineteenth century when a Russian zoologist named Elie Metchnikoff proposed that inflammation may be protective rather than harmful [2].

In summary, inflammation is a reaction of our bodies, driven by the immune system, against potentially harmful elements. Inflammation is then good and necessary for the preservation of our health.

\section{Wait, If Inflammation Is Protecting Us, Why Do We Use Anti-Inflammatory Medicines to Stop It?}

Although the job of the inflammatory reaction is to send our internal troops to the site of injury to protect us, sometimes this response is so strong that it causes some collateral damage. As explained earlier, cells from the immune system are brought to the area, thanks to the increase in blood flow. The earliest cells to arrive are the neutrophils, which are a type of white blood cell that contains small sacs (also called vesicles) inside, filled up with protective factors such as anti-bacterial proteins or enzymes that can help to break down infectious organisms. The neutrophils then release those factors into the inflamed area to neutralize the infecting virus or bacteria. However, if too many of these factors are released from neutrophils at the same time, then the factors will also cause damage to the body. In those cases, too much inflammation can become dangerous. Anti-inflammatory medicines can then be used to help control the inflammatory reaction, to prevent it from overshooting. In summary, we use anti-inflammatory medicines, not to stop inflammation completely, but to help to "balance" the benefits of inflammation against the potential collateral damage that it may cause to the body.

\section{Why Aspirin Is Not Always Enough}

Many different types of anti-inflammatory drugs are available with or without a prescription, for example aspirin, paracetamol, ibuprofen, and dexamethasone. Why are scientists still performing research to find new ones? Most of the anti-inflammatory drugs that are available are quite effective for a type of inflammatory reaction called "acute" inflammation. 
Acute inflammation is the kind that occurs in the examples mentioned earlier (sore throat, stubbed pinky toe, etc.), in which the reaction happens very quickly and has a short duration (a few days or weeks). However, there is another type of inflammation that is less well understood by doctors and scientists and is called "chronic" inflammation [3]. Chronic inflammation can last several months or even years and occurs in diseases such as rheumatoid arthritis (inflammation in the joints), atherosclerosis (a disease of the blood vessels), or even obesity. This type of inflammation is very difficult to control, in some cases, because the medicines are not very effective and in other cases because patients experience side effects after taking the medicines for too long. Those patients can then suffer the effects of chronic inflammation for years or even for their entire lives, and that is why scientists are still trying very hard to discover new anti-inflammatory medicines to help patients with chronic inflammation.

PRO-INFLAMMATORY FACTORS

Cells and chemical substances that are produced during the inflammatory response with the mission of attacking and neutralizing the harmful stimulus. Examples include prostaglandins, cytokines, chemokines, and interleukins.

PRO-RESOLVING FACTORS

Cells and chemical substances that are produced during the inflammatory response with the mission of stimulating healing and tissue repair, leading to a recovery of balance in the body. Examples include resolvins, melanocortins, and annexin A1.

\section{THE SECRET ELEMENTS OF INFLAMMATION}

\section{The Pro-Inflammatory Factors}

The four pillars of inflammation that Celsus was able to identify are caused by what we call the "pro-inflammatory" factors. Upon injury, tissues release chemical substances such as prostaglandins, which cause the enlargement of blood vessels leading to redness, heat, and swelling. Together with prostaglandins, other types of pro-inflammatory substances include things called chemokines, cytokines, and interleukins. These are chemicals that serve as flag signals to guide the immune cells that are circulating in the blood to the site of injury. Then, these immune cells enter the tissue and get activated, releasing the enzymes and anti-bacterial products contained in their little vesicles. These factors are called pro-inflammatory factors, and their purpose is to neutralize the injurious (i.e., damaging) element.

However, scientists around the world have recently discovered another type of factors that participate in the inflammatory reaction called "pro-resolving" factors, which serve a very different purpose...

\section{Who Cleans up After the Battle?}

What really happens in the body during an inflammatory reaction is quite similar to a battleground, where two armies (the body and the diseasecausing bacteria) fight against each other. During the battle, many cells and bacteria may die and need to be removed from the affected area, and the damaged tissue needs to be repaired. The pro-resolving factors are the ones in charge of tissue repair after the elimination of 
Figure 2

The new pro-resolving strategy

Inflammation is a defense mechanism and it is beneficial inflammation protects our bodies from infection and injury. However, excessive inflammation can lead to collateral damage, and that's why we use medicines to reduce it. (A) The traditional anti-inflammatory medicines work by blocking and preventing the actions of immune cells such as neutrophils and monocytes and the actions of the chemical factors that they produce (like cytokines, interleukins, etc.). (B) On the other hand, the new "pro-resolving" strategy consists of medicines that activate processes in cells like macrophages and fibroblasts to stimulate wound healing and damage repair. the disease-causing bacteria. The pro-resolving factors are made of both cells and chemicals. The main type of immune cells involved in the regenerating phase (which is also called the pro-resolving phase) are called the M2-macrophages. The chemicals involved in the proresolving phase have names such as resolvins, melanocortins, annexin A1, and protectins, among others [4-6]. The job of both the pro-resolving cells and chemicals is to repair the damaged tissues after the injury. The pro-resolving factors do not produce collateral damage, because they are not directly involved in the fight itself, but in the cleaning up and repair once the danger is gone [7].

The discovery of the pro-resolving factors represents a great achievement and may have strong implications in future medicines, because these factors may revolutionize the way we treat inflammation, especially the chronic inflammatory diseases mentioned earlier, which are so difficult to control.

\section{PRO-RESOLVING DRUGS: THE MEDICINES OF THE FUTURE?}

After the discovery of the existence of pro-resolving factors, which have the mission of repairing the damaged tissues and restoring the body to a state of balance, scientists realized that inflammation could be treated in a radically different way than doctors had been treating it for years (Figure 2). In the past, the typical way to treat inflammation

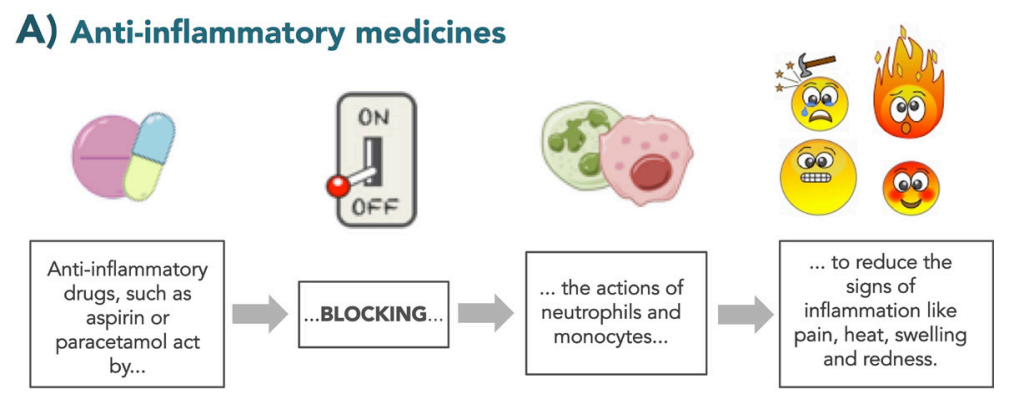

B) Pro-resolving medicines

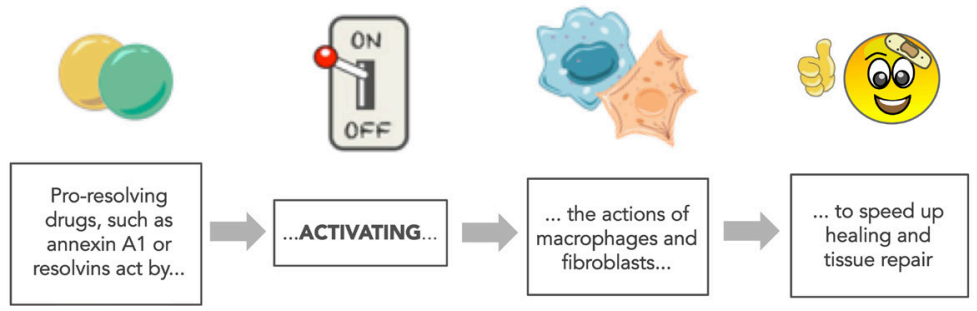

Figure 2 
was always to try to reduce the action of the pro-inflammatory components of inflammation, in order to reduce the collateral damage to the body. However, scientists now believe that we can instead increase the action of the pro-resolving factors [8] to start the healing process more quickly! In addition, we also now know that the pro-inflammatory factors are necessary to activate the pro-resolving factors [9]. In other words, the pro-inflammatory factors act as signals for the body to produce and send the pro-resolving, reparative factors after the battle. This is important, because it means that if we completely eliminate the pro-inflammatory factors by using strong anti-inflammatory medicines, then later we will not have the signals that stimulate healing. That is why some anti-inflammatory medicines are said to be "resolution-toxic": they stop pain and swelling but they also stop the healing! So, a proresolving strategy to control inflammation seems to be safer, because it will involve using drugs that mimic the way the body naturally resolves inflammation. However, this does not mean that we should discard all the older anti-inflammatory drugs. In fact, a combination of both types of medicines might be very beneficial.

\section{CONCLUSION}

The way we understand and deal with inflammation is changing as we now have much more knowledge about all of the components of the inflammatory response, including the pro-inflammatory and the pro-resolving factors. We now know that inflammation is a necessary, protective reaction of our bodies without which we would not survive, although some collateral damage sometimes happens. The switch from reducing inflammation to increasing its resolution is now widely accepted among the scientists, and it brings new hope for those patients for whom the usual anti-inflammatory drugs do not work. The arsenal of protective pro-resolving factors we know to date is large, although we also believe that many more pro-resolving factors remain to be discovered by the scientists of the future.

\section{ACKNOWLEDGMENTS}

I would like to thank Mauro Perretti, Sophie Wahalatantri and Scarlett Bland for their critical review of the manuscript. I also thank Arthritis Research UK (grant 21274) for funding my research. 


\section{REFERENCES}

1. Rivas, F. 2010. In this issue: inflammation. Cell 140:755-7. doi: 10.1016/ j.cell.2010.03.007

2. Gordon, S. 2008. Elie Metchnikoff: father of natural immunity. Eur. J. Immunol. 38:3257-64. doi: 10.1002/eji.200838855

3. Tabas, I., and Glass, C. K. 2013. Anti-inflammatory therapy in chronic disease: challenges and opportunities. Science 339:166-72. doi: 10.1126/science. 1230720

4. Montero-Melendez, T. 2015. ACTH: the forgotten therapy. Semin. Immunol. 27:216-26. doi: 10.1016/j.smim.2015.02.003

5. Serhan, C. N., Chiang, N., and Van Dyke, T. E. 2008. Resolving inflammation: dual anti-inflammatory and pro-resolution lipid mediators. Nat. Rev. Immunol. 8:349-61. doi: 10.1038/nri2294

6. Perretti, M., and D'Acquisto, F. 2009. Annexin A1 and glucocorticoids as effectors of the resolution of inflammation. Nat. Rev. Immunol. 9:62-70. doi: 10.1038/nri2470

7. Ortega-Gomez, A., Perretti, M., and Soehnlein, O. 2013. Resolution of inflammation: an integrated view. EMBO Mol Med. 5:661-74. doi: 10.1002/ emmm.201202382

8. Perretti, M., Leroy, X., Bland, E. J., and Montero-Melendez, T. 2015. Resolution pharmacology: opportunities for therapeutic innovation in inflammation. Trends Pharmacol. Sci. 36:737-55. doi: 10.1016/j.tips.2015.07.007

9. Serhan, C. N., and Savill, J. 2005. Resolution of inflammation: the beginning programs the end. Nat Immunol. 6:1191-7. doi: 10.1038/ni1276

SUBMITTED: 04 June 2018; ACCEPTED: 05 September 2018;

PUBLISHED ONLINE: 21 September 2018.

EDITED BY: Bergithe Eikeland Oftedal, University of Bergen, Norway

CITATION: Montero-Melendez T (2018) May Inflammation Be With You! Front. Young Minds. 6:51. doi: 10.3389/frym.2018.00051

CONFLICT OF INTEREST STATEMENT: The author declares that the research was conducted in the absence of any commercial or financial relationships that could be construed as a potential conflict of interest.

COPYRIGHT @ 2018 Montero-Melendez. This is an open-access article distributed under the terms of the Creative Commons Attribution License (CC BY). The use, distribution or reproduction in other forums is permitted, provided the original author(s) and the copyright owner(s) are credited and that the original publication in this journal is cited, in accordance with accepted academic practice. No use, distribution or reproduction is permitted which does not comply with these terms. 

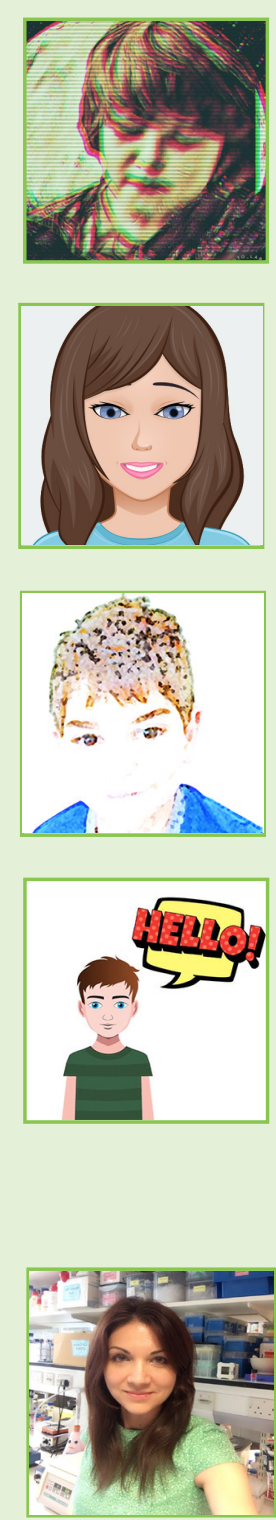

\section{YOUNG REVIEWERS}

\section{CHARLIE, AGE: 11}

I have just started at High School and my favourite subjects are maths and PE. I also like playing the baritone and Plants vs Zombies Garden Warfare 2.

\section{ELIANA, AGE: 11}

I have many hobbies! I love reading, writing, science, history, politics, acting, running, basketball, and tennis. I am very active in my community and participate in many volunteer opportunities.

\section{MILAN, AGE: 9}

Milan's mother is Peruvian and his father, French, but he was born in Bolivia. Everybody in the family says that his head is full of numbers because he likes to calculate everything, but he also enjoys swimming, board games and reading about magic adventures in historical places.

\section{RAFAEL, AGE: 10}

Loves Harry Potter, Lego and Minecraft.

\section{AUTHOR}

\section{TRINIDAD MONTERO-MELENDEZ}

Trinidad Montero-Melendez graduated with a degree in Pharmacy from the University of Granada -Spain, where she also earned her PhD in Molecular Biology. She joined Professor Perretti's lab in 2008, where she has been studying the actions of the proresolving factors and developing new medicines to threat patients suffering from chronic inflammation. In her spare time, Trini enjoys painting, inventing recipes and planting seeds to see the new plants grow! *t.monteromelendez@qmul.ac.uk 